\title{
As dietas de Rousseau: o caso do Emílio ${ }^{73}$

\author{
The diets of Rousseau: Emile's case
}

\section{Mauro Dela Bandera Arco Júnior}

Doutor em filosofia pela USP

\begin{abstract}
Resumo: O tema das dietas alimentares, enganosamente considerado tema periférico, aparece em muitos escritos de Rousseau, das obras consideradas autobiográficas até as ditas teóricas, passando pela Nova Heloísa e por muitos outros textos. O Emílio não seria diferente. O objetivo deste artigo é, pois, abordar duas formulações desta temática presentes ao longo do Emílio, a saber: i) a preferência pelas dietas simples e vegetarianas e, sobretudo, ii) as relações entre as dietas e a proposta antropológica do autor, tal como desenhada no Discurso sobre a desigualdade.
\end{abstract}

Palavras-chaves: Rousseau; Antropologia; Dietas; Emílio.

Abstract: Deceitfully considered a peripheral subject, the theme of diets appears in different writings of Rousseau, comprising autobiographical and theoretical works, including New Heloise, and many other texts. It would not be different in Emile's case. The purpose of this article is to address two formulations of this theme throughout Emile, namely: i) the preference for simple and vegetarian diets and, especially, ii) the relations between the diets and the author's anthropological proposal, as configured in the Discourse on inequality.

Keywords: Rousseau; Anthropology; Diets; Emile.

73 Uma versão preliminar deste artigo foi apresentada em nossa tese de doutorado,A origem da alteração e a alteração de origem: antropologias de Rousseau,defendida em 2018 na FFLCH/USP. 
$\mathbf{O}^{2}$ tema das dietas alimentares - intimamente ligado na história da filosofia à moral e à medicina - aparece em muitos escritos de Rousseau, desde as obras consideradas autobiográficas até as ditas teóricas, passando também pela Nova Heloísa e muitos outros textos. Todos eles revelam uma constante, a saber: a preferência dada aos alimentos de origem vegetal compreendendo, nesta categoria, o leite e seus derivados - e a aversão ao consumo de carnes ${ }^{74}$. Emílio "ama os bons frutos, os bons legumes, a boa nata e as boas pessoas" (Rousseau, 1969, p. 465); Sofia "gosta de laticínios e de doces; gosta de confeitaria e de sobremesas (les entremets), mas pouco de carne" (Rousseau, 1969, p. 749). Jean-Jacques anuncia, nas páginas de suas Confissões, as mesmas predileções alimentares: "não conhecia e ainda não conheço melhor alimento que uma refeição rústica. Pode-se ter sempre a certeza de que me regalam perfeitamente com leite, ovos, ervas, queijo, pão de rolão (pain bis) e vinho razoável" (Rousseau, 1959, p. 72). O mesmo vale para Julie que, quase como uma "verdadeira pitagórica", "não gosta de carne, de guisados, nem de sal e nunca provou vinho puro: vegetais saudáveis, ovos, nata, frutas - eis sua alimentação habitual" (Rousseau, 1961, p. 453) ${ }^{75}$. A importância da alimentação é tanta que Saint-Preux vê nos hábitos alimentares uma marca de caráter: "em geral, penso que se poderia frequentemente encontrar algum índice do caráter das pessoas na escolha dos alimentos que elas preferem" (Rousseau, 1961, p. 453).

Apesar da riqueza do tema, não mapearemos todas as suas ocorrências, sentidos ou implicações. Por conta dos limites deste

\footnotetext{
$74 \quad$ Um esclarecimento se faz aqui necessário. A presença constante do leite e derivados nas dietas de Rousseau e de seus personagens se justifica, pois, aos olhos do autor, "o leite, mesmo que elaborado no corpo do animal, é uma substância vegetal” (Rousseau, 1969, p. 275). Tal convicção encontra respaldo nas teorias da época. Rousseau chega a citar em nota Antonio Celestino Cocchi Mugellano (1695-1758) que, em seu Del vitto pitagorico per uso della medicina (1743), sustenta "que o leite das fêmeas herbívoras, mesmo que produzido no interior do corpo animal, ainda não perdeu todas suas qualidades vegetais" (Menin, 2012, p. 99).

75 De acordo com essa mesma passagem da Nova Heloísa, Julie é uma grande apreciadora de peixes, por isso ela não é uma verdadeira pitagórica: "sem o peixe que tanto ama, ela seria uma verdadeira pitagórica".
} 
trabalho, não abordaremos todos esses textos ${ }^{76}$. Limitaremos o escopo desta investigação ao Emílio, suas eventuais proximidades com o segundo Discurso e o Ensaio, bem como as possíveis relações existentes entre Rousseau e outros autores do período.

A relação entre hábitos alimentares e caráter das pessoas está presente no Emílio e no Discurso sobre a desigualdade. Nas diversas notas que compõem o segundo Discurso, Rousseau recorre à anatomia comparada ${ }^{77}$ e a outras disciplinas, dentre elas a história natural e os relatos de viagens, a fim de provar que o homem seria naturalmente herbívoro. A organização fisiológica dos intestinos, a dentição, as mamas e o número de filhos por gestação atestam essa disposição alimentar.

A defesa do vegetarianismo era, nos meados do século XVIII, um lugar-comum entre os escritores. Em 1740, George Cheyne (1671-1743) publicou em Londres um ensaio sobre regime alimentar (An Essay on Regimen), em que critica a dieta carnívora e tece um elogio ao vegetarianismo. Muito antes dele, em 1714, Mandeville, na Fable des abeilles, também atacara a dieta baseada na ingestão de carnes $^{78}$. Esse tópico era um verdadeiro clichê ou um tema corriqueiro para médicos, filósofos e naturalistas.

Todavia, mais importante do que a constatação de um lugar-comum, é fundamental perceber que autores como La Mettrie em seu Homem-máquina (1748) e Buffon no tomo IV de sua História natural (1753) podem ter sugerido a Rousseau as vantagens do regime herbívoro. O artigo "Le Cheval", da Histoire naturelle, pode muito bem ter indicado a Rousseau quais seriam as vantagens da vida vegetariana, a saber, a paz. Citemos Buffon:

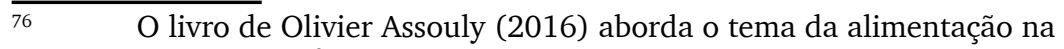
obra de Rousseau de forma exaustiva, principalmente no que tange às suas relações com a necessidade, o prazer do paladar, o apetite, a produção agrícola, a economia política, dentre outras.

$77 \quad$ Nas notas, Rousseau se vale das competências da anatomia comparada, muito embora o início da primeira parte de seu livro afirme que esta disciplina, que realizara poucos progressos, ainda produzia conhecimentos incertos (Rousseau, 1964, p. 134).

78 Mandeville opõe-se veementemente ao consumo de carne, afirmando que o organismo humano é normalmente incapaz de tolerar sua ingestão (Mandeville, 1998, p. 133-142). 
como a relva e as plantas bastam para sua alimentação, como eles [os cavalos] têm-nas em abundância para poder satisfazer seu apetite e como eles não têm nenhum gosto pela carne animal, eles não travam guerra por causa dela, não a travam entre si, não disputam entre si sua subsistência, nunca têm a ocasião de rapinar uma presa ou de arrancar um bem, fonte ordinária de querelas e combates entre os animais carnívoros; eles vivem, portanto, em paz, porque seus apetites são simples e moderados, e eles têm o suficiente para nada desejar. (Buffon, 2010, p. 255).

La Mettrie sustentara uma posição bastante similar, com a vantagem de nivelar - como lhe é habitual - o comportamento animal ao humano. É verdade que a relação que La Mettrie estabelece é entre a carne crua ou mal passada - fonte de crueldade e ferocidade - e a carne cozida, e não entre carnes e vegetais, tal como se encontra em Buffon. Apesar disso, poder-se-ia a partir do Homem-máquina pensar que uma alimentação baseada exclusivamente em vegetais produziria um efeito ainda melhor, um temperamento ainda mais brando e ameno nos seres humanos.

A carne crua deixa os animais ferozes, os homens, pela mesma alimentação, também se tornariam ferozes; isto é tão verdadeiro que a nação inglesa, que não consome a carne tão cozida quanto nós, mas vermelha e sangrenta, parece participar desta ferocidade em maior ou menor grau, em parte devido a esses alimentos e a outras causas que apenas a educação poderia tornar impotentes. Essa ferocidade produz na alma o orgulho, o ódio, o desprezo a outras nações, a insolência e outros sentimentos que depravam o caráter; os alimentos grosseiros criam um espírito pesado e rude, cuja preguiça e indolência são os atributos favoritos. (La Mettrie, 1981, p. 152)

$79 \quad$ No início do capítulo IX do Ensaio sobre a origem das línguas, Rousseau afirma, valendo-se de exemplos bíblicos e da antiguidade clássica, que os povos - "cuja origem conhecemos" - eram grandes devoradores de carne. O autor sublinha também - assim como em La Mettrie - a imagem, recorrente no século XVIII, dos ingleses como exímios comedores de carne e, por isso, com uma propensão à crueldade. "Geralmente, entre todos os povos cuja origem conhecemos, os primeiros bárbaros mostram-se mais vorazes e carnívoros do que agricultores e granívoros. Os gregos nomeiam o primeiro que lhes ensinou a cultivar a terra e parece que só bem tarde conheceram essa arte. Quando dizem, porém, que antes de Triptólemo só viviam de avelã, afirmam algo que não pode ser verdadeiro e que é desmentido pela sua própria história, pois antes de Triptólemo comiam carne, tanto que ele os proibiu de comê-la. De resto, não se sabe que tenham levado em grande consideração tal proibição. Nos festins de Homero matava-se um boi para regalar os hóspedes, como hoje se mataria um leitãozinho. Lendo que Abraão serviu um bezerro a três pessoas, que Eumeu mandou assar dois cabritos para o jantar de Ulisses e que o mesmo fez Rebeca para o de seu marido, pode-se imaginar 
Rousseau e muitos outros autores também assumem esse mote do século XVIII em seus escritos. Quando se trata - no segundo Discurso - da defesa de uma dieta composta exclusivamente por frutas, verduras e raízes, é a paz a principal vantagem que almeja alcançar. Neste sentido, a dieta herbívora é mais um dos argumentos mobilizados para criticar o estado natural de guerra hobbesiano. Contrariamente ao pensamento de Hobbes, o homem não é naturalmente belicoso e a não disposição em se nutrir de alimentos cárneos é uma prova desta não belicosidade.

Sendo a presa quase o único motivo de combate entre os animais carnívoros, e vivendo os frugívoros entre si em uma paz contínua, se a espécie humana fosse deste último gênero, claro que teria tido muito mais facilidade de subsistir no estado de natureza, e muito menos necessidade e ocasião de dele sair. (Rousseau, 1964, p. 199)

De forma análoga, no livro II do Emúlio, o autor afirma que, em geral, "os grandes devoradores de carne" são homens cruéis e ferozes:

uma das provas de que o gosto pela carne não é natural ao homem é a indiferença das crianças em relação a esse alimento e a preferência que dão a alimentos vegetais, como os laticínios, a confeitaria, as frutas, etc. Importa sobretudo não desnaturar esse gosto primitivo, e não tornar as crianças carnívoras: se não for por sua saúde, que seja por seu caráter, pois, como quer que se explique a experiência, é certo que os grandes devoradores de carne são, em geral, mais cruéis e ferozes do que os outros homens. [...] Todos os selvagens são cruéis e seus costumes não os levam a sê-lo: esta crueldade vem de seus alimentos. (Rousseau, 1969, p. 411)

No Emílio, particularmente ao longo dos livros I e II do mesmo modo que em parte considerável da seção sobre a "Idade da natureza" do manuscrito de Favre (primeira versão do Emílio) -, Rousseau desenvolve diversos argumentos acerca das dietas humanas, tanto no que diz respeito à questão do regime mais apropriado às amas de leite ${ }^{80}$ quanto à dieta mais adequada à criança. Inclusive, se nos fiarmos no próprio teste-

que tremendos devoradores de carne eram os homens daqueles tempos. Para conceber como eram as refeições dos antigos, basta ver a dos selvagens de hoje - quase disse: a dos ingleses" (Rousseau, 1995, p. 397-398).

$80 \quad$ "Nossa primeira preceptora é nossa nutriz", nos diz Rousseau (Rousseau, 1969, p. 252). 
munho de Rousseau, a questão do uso da carne seria um ponto importante da primeira parte da obra, pelo menos tal como imaginada originalmente pelo autor. É o que diz o manuscrito R. 18 (antigo 7842) da Biblioteca de Neuchâtel: "o primeiro livro do Emílio" seria "sobre vermes gerados pelo uso de carne." (Rousseau, 1969, p. 1321, note 1) ${ }^{81}$.

No que diz respeito ao texto definitivo, é sabido que Rousseau não se mostra muito favorável ao uso de nutrizes e chega inclusive a manifestar essa rejeição em diversas passagens: "a verdadeira ama de leite é a mãe", nos diz o autor. Ele retoma as palavras de Buffon que, em 1749, havia criticado o uso das nutrizes e, por conseguinte, havia recomendado o aleitamento realizado pela própria mãe: "se as mães alimentassem suas crianças", escreve o diretor do jardim do rei,

supõe-se que elas seriam mais fortes e mais vigorosas, devendo ser o leite de sua mãe melhor para elas do que o leite de outra mulher, já que o feto se alimenta de um licor leitoso que é muito similar ao leite que se forma nas mamas; a criança já está, por assim dizer, acostumada com o leite de sua mãe, ao passo que o leite de outra nutriz é, para ela, um novo alimento. (Buffon, 2008, p. 493).

Além disso, como somente a ternura materna é capaz de uma vigilância contínua e da realização dos pequenos cuidados tão necessários para a conservação e o bem-estar das crianças, não é crível esperar o mesmo empenho e o mesmo comportamento "de amas de leite mercenárias e grosseiras" (Buffon, 2008, p. 482).

Contudo, dos males o menor: não sendo realizável o aleitamento materno, é fundamental escolher bem uma nutriz. Nos dizeres de Buffon, "todo mundo sabe o quanto é importante para a saúde das crianças escolher boas nutrizes: é indispensável que elas sejam saudáveis e se portem bem" (Buffon, 2008, p. 493). Em sintonia com essas palavras, Rousseau também demonstra uma preocupação especial na escolha da ama de leite. A seus olhos, ela deve ser "saudável tanto de coração quanto de corpo" (Rousseau, 1969, p. 273).

Ms. R 18, fo $52 \mathrm{v}^{\mathrm{o}}$, Bibliothèque publique et universitaire de Neuchâtel (Suisse). 
Sobre os alimentos que lhe são mais adequados, é preciso seguir o padrão de sua alimentação, sem que haja mudanças bruscas:

é preciso que a nutriz viva com um pouco mais de comodidade, que coma alimentos um pouco mais substanciosos, mas que não mude completamente sua maneira de viver, pois uma mudança repentina e total, mesmo que seja para melhor, é sempre perigosa para a saúde; e, já que seu regime ordinário a manteve ou a tornou sadia e bem constituída, para que fazê-la mudar? (Rousseau, 1969, p. 274)

Em vez de alterar de modo radical a alimentação ordinária seguida pelas amas de leite, "basta dar-lhes uma alimentação mais abundante e melhor escolhida em sua espécie" (Rousseau, 1969, p. 276). Por isso, a prescrição de Rousseau ${ }^{82}$ não pode significar que tudo deve ser alterado, mas tão somente que é preciso arranjar as coisas de um modo diferente.

Nas páginas do Emílio, portanto, o termo "regime" relaciona-se primeiramente à qualidade e à preparação dos alimentos ingeridos tanto pela ama de leite quanto pela criança. Nos dois casos, Rousseau propõe uma alteração nas regras da cozinha em favor de uma dieta calcada em uma maior simplicidade ${ }^{83}$ - que pode ser composta até mesmo por carnes -, já que é tão somente o tempero que torna os alimentos malsãos. No que diz respeito especificamente à alimentação da criança, pode-se ler:

os gostos mais naturais devem ser também os mais simples [...]. Nosso primeiro alimento é o leite; só nos acostumamos aos sabores fortes gradualmente; de início, eles nos repugnam. Frutas, legumes, ervas e, enfim, algumas carnes grelhadas, sem tempero e sem sal, fizeram os festins dos primeiros homens. [...] quanto mais simples nossos gostos, mais universais eles são; as repugnâncias mais comuns recaem sobre os pratos compostos. Alguma vez se viu uma pessoa desgostar de água ou de pão? Eis a marca da natureza, eis também nossa regra. Conservemos na criança seu gosto primitivo o mais possível; que sua alimentação seja comum e simples, que seu paladar só se familiarize com sabores pouco marcantes e que não adquira um gosto exclusivo. (Rousseau, 1969, p. 408).

Mas não é só isso. O termo regime também é considerado, para além das variantes alimentares, em um sentido mais $82 \quad$ "Reformai as regras de vossa cozinha" (Rousseau, 1969, p. 276). 83 Sobre a noção de simplicidade na cozinha, ver o livro de Olivier Assouly (2016, p. 47). 


\section{amplo que inclui, como em Hipócrates, os ares ${ }^{84}$, os exercícios esportivos, a ginástica, o trabalho ${ }^{85}$, os banhos ${ }^{86}$, dentre tantas}

$84 \quad$ Na esteira da acepção hipocrática de regime, Rousseau insiste sobre a influência decisiva de fatores exógenos. Ele lembra o papel desempenhado pelo ar nos primeiros anos de vida de uma criança. Citemos: "é sobretudo nos primeiros anos da vida que o ar age sobre a constituição das crianças. Em uma pele delicada e mole, ele penetra por todos os poros, afeta poderosamente esses corpos nascentes e deixa neles impressões que nunca se apagam. Desse modo, eu não concordaria em que se tirasse uma camponesa de sua aldeia para fechá-la em um quarto na cidade e fazê-la amamentar a criança em casa; prefiro que a criança vá respirar o bom ar do campo do que o mau ar da cidade" (Rousseau, 1969, p. 276). Ou ainda: "as cidades são o abismo da espécie humana. Ao cabo de algumas gerações, as raças morrem ou degeneram. É preciso renová-las, e é sempre o campo que traz essa renovação. Enviai, pois, vossos filhos para que se renovem e retomem, em meio aos campos, o vigor que se perde no ar insalubre dos lugares demasiadamente povoados" (Rousseau, 1969, p. 277).

85 "Para saber qual é o regime mais útil à vida e à saúde, basta saber qual regime adota os povos que se cuidam melhor, que são mais robustos e que vivem por mais tempo. [...] Não me deterei em provar nos pormenores a utilidade dos trabalhos manuais e dos exercícios do corpo para reforçar o temperamento e a saúde; é o que ninguém discute: os exemplos das vidas mais longas são quase todos tirados de homens que mais fizeram exercícios e mais suportaram a fadiga e o trabalho*" (Rousseau, 1969, p. 271-272).

"Eis um exemplo tirado de documentos ingleses, o qual não posso deixar de relatar, tantas são as reflexões que oferece relativas ao meu assunto:

"Um particular chamado Patrice Oneil, nascido em 1647, acaba de se casar em 1760 pela sétima vez. Ele serviu nos dragões no décimo sétimo ano do reinado de Carlos II, e em diferentes regimentos até 1740, quando obteve sua aposentadoria. Fez todas as campanhas do rei Guilherme e do duque de Marlborough. Esse homem nunca bebeu senão cerveja ordinária; sempre se alimentou de vegetais e só comeu carne em algumas refeições que oferecia à sua família. Seu costume sempre foi levantar-se e deitar-se com o sol, a menos que os deveres o impedissem. Está atualmente em seu centésimo décimo terceiro ano, ouvindo bem, em boa forma e caminhando sem bengala. Apesar da idade avançada, não permanece ocioso um só momento, e todos os domingos vai à sua paróquia, acompanhado dos filhos, netos e bisnetos." 86 "Uma vez estabelecido o uso do banho, ele não deve mais ser interrompido, e é importante conservá-lo por toda a vida. Considero-o não apenas do ponto de vista da limpeza e da saúde atual, mas também como uma precaução salutar para tornar mais flexível a textura das fibras e fazê-las ceder sem esforço e sem risco aos diversos graus de calor e de frio. Para isso, gostaria que, durante o crescimento, fôssemos pouco a pouco acostumados a nos banhar algumas vezes em águas quentes, de todos os graus suportáveis, e frequentemente em águas frias, de todos os graus possíveis. Assim, depois de habituados a suportar as diversas temperaturas da água, que, sendo um fluído mais denso, toca em mais pontos e afeta mais, iríamos nos tornar quase insensíveis àquelas do ar.” (Rousseau, 1969, p. 278). 
outras $\operatorname{coisas}^{87}$. Aliás, muitos desses diferentes aspectos compreendidos na ideia de regime aparecem ao longo da História natural, particularmente no segundo tomo. Podemos citar a crítica aos ares insalubres das cidades e, consequentemente, a recomendação do ar do campo (Buffon, 2008, p. 494) ${ }^{88}$, bem como do hábito de se valer de banhos frios ${ }^{89}$.

Nesses termos, o regime não pode ser considerado como um conjunto de regras universais e uniformes. Como bem disse Foucault, o regime é "uma espécie de manual para reagir às situações diversas nas quais é possível encontrar-se; um tratado para ajustar o comportamento de acordo com as circunstâncias" (Foucault, 1984, p. 97). É por isso que o indivíduo deve levar em consideração um sem-número de variáveis para praticar exercícios (naturais - andar, passear - e os violentos corridas e lutas) e determinar sua intensidade, tomar banhos (quentes ou frios), alimentar-se (a qualidade e a quantidade de nutrientes absorvidos), realizar as evacuações, purgações e vômitos, as relações sexuais, etc. Estas variáveis são: o clima, as estações, as horas do dia, o grau de umidade e de secura, de calor e de frescor, os ventos, os caracteres próprios de uma determinada região, a idade, etc.

$87 \quad$ Sobre esse sentido amplo da dieta, ver as duas primeiras seções ("Do regime em geral" e "A dieta dos prazeres") do capítulo II (Dietética) da História da sexualidade 2 (Foucault, 1984, p. 91-106).

$88 \quad$ No que diz respeito à medicina e à teoria dos climas, Jean Ehrard cita inúmeros trabalhos e temas de concursos de várias academias de ciências da primeira metade do século XVIII, que tocam a questão da influência do ar sobre os homens e da qualidade do ar que se respira. Com isso, a história da teoria dos climas no XVIII se mostra inseparável de uma pesquisa médica que atente, sobretudo, à ação fisiológica e patológica do ar sobre os seres vivos: o ar como causa de doenças de pele; a influência da temperatura e da umidade do ar na conformação das fibras e dos tecidos, etc. (Ehrard, 1994, p. 696-705).

$89 \quad$ Buffon cita alguns casos de povos que se banham em água gelada. "Tem-se sempre neste país [França] a sábia precaução de apenas banhar a criança com licores mornos, todavia, nações inteiras, até mesmo as que vivem em climas frios, têm o hábito de mergulhar seus filhos em água fria assim que nascem, sem que lhes acometa mal algum; dizem até que os lapões deixam seus filhos na neve até que o frio seja tanto a ponto de lhes interromper a respiração e, então, os mergulham em um banho de água quente" (Buffon, 2008, p. 475). Mais adiante, Buffon complementa dizendo: "por mais delicada que seja a infância, esta idade é a menos sensível ao frio do que todas as outras épocas da vida" (Buffon, 2008, p. 490). 
De certa maneira, as variáveis válidas para o regime hipocrático também podem ser aplicadas às ideias de Rousseau sobre alimentação e sobre os banhos. O genebrino escreve acerca da alimentação a seguinte passagem:

embora tenhamos a faculdade de transformar outros em nossa própria substância, a escolha não é indiferente: nem tudo é alimento para o homem; e, das substâncias que podem sê-lo, há as que são mais ou menos convenientes, segundo a constituição de sua espécie, segundo o clima em que habite, segundo seu temperamento particular, e segundo a maneira de viver que seu estado lhe prescreve. (Rousseau, 1969, p. 407)

O preceptor assume, então, a tarefa de armar Emílio para que ele próprio consiga lidar com a multiplicidade e a instabilidade das circunstâncias. Em suma, Rousseau quer que Emílio possa viver bem em qualquer lugar. Não se trata de fazê-lo deste ou daquele território e/ou condicionado a um determinado alimento e preparo específicos, mas antes, de lhe dar condições de perseguir seus meios de subsistência não importando onde se encontre. Em suas palavras, "o homem de um país não se torna o de outro" (Rousseau, 1969, p. 408). Por isso, ele insiste para que não se eduque um homem com os hábitos culturais limitados de um só país, com gosto exclusivos, portanto, excludentes: "não façamos com que morra de fome em outros países se não levar consigo por toda parte um cozinheiro francês, nem que diga um dia que só se sabe comer na França" (Rousseau, 1969, p. 409).

Portanto, o tema das dietas se apresenta nas páginas do Emílio enquanto um elogio das dietas simples, mais naturais e, ao mesmo tempo, enquanto um conjunto de reflexões capaz de facilitar a variabilidade e a plasticidade humanas que também serão importantes ao longo do segundo Discurso -, de modo a preservar a natureza adaptável do ser humano às circunstâncias. De acordo com Rousseau, "o homem que ainda não é de nenhum país adaptar-se-á sem dificuldade aos usos de qualquer outro" (Rousseau, 1969, 408). Tal ideia encontra bastante lastro nas reflexões antropológicas.

Para Rousseau, ao longo do Discurso sobre a desigualdade, a variação e a plasticidade das dietas humanas elucidam 
bem o sistema de funcionamento da perfectibilidade. Os homens possuíam aparentemente uma alimentação semelhante à dos animais. No entanto, a humanidade se afasta da vida animal por uma ruptura de dieta, sendo o animal condenado a permanecer (e a comer) sempre o mesmo. Esta variação marca a exclusividade humana e indica a perfectibilidade. Além de operar a distinção entre animalidade e humanidade, importa saber que a perfectibilidade também é o mecanismo de distinção intraespecífica entre os homens. Segue-se que um grupo humano se separa e se distingue culturalmente dos outros por meio das escolhas dos alimentos que entram em sua dieta ${ }^{90}$.

O Discurso sobre a desigualdade nos conta - e o Ensaio o segue de perto - a história desse processo de distinção e variação, ou seja, a distinção do homem em relação aos animais e, sobretudo, em relação aos outros homens. Neste segundo movimento, ele nos mostra como se dá a construção das identidades humanas coletivas. Com isso, Rousseau desenvolve um pensamento comprometido com a variedade da espécie humana e de sua natureza, engajado em mostrar a diferença entre os caracteres marcantes da humanidade de cada agrupamento social disperso temporal e geograficamente.

Em consonância a esses objetivos, Emílio deve adequarse e adaptar-se a qualquer cultura, por conseguinte, a qualquer dieta alimentar. Por isso, um dos trabalhos do preceptor é justamente facilitar essa adaptação, o que indica a existência (cara ao pensamento antropológico de Rousseau) de diferenças e variações entre os homens e seus agrupamentos. Deste modo, vemos a importância das dietas alimentares para a construção da antropologia de Rousseau.

$90 \quad$ Diz o autor no segundo Discurso: "ao longo do mar e dos rios", os homens "inventaram a linha e o anzol e se tornaram pescadores e ictiófagos; nas florestas eles fizeram arcos e flechas e se tornaram caçadores" (Rousseau, 1964, p. 165). 


\section{Referências:}

ASSOULY, Olivier. Les nourritures de Jean-Jacques Rousseau: cuisine, goût et appétit. Paris: Classiques Garnier, 2016.

BUFFON. Histoire naturelle. T. II. Paris: H. Champion 2008.

BUFFON. Histoire naturelle. T. IV. Paris: H. Champion 2010.

EHRARD, Jean. Lidée de nature en France dans la première moitié du XVIIIe siècle. Paris: Albin Michel, 1994.

FOUCAULT, Michel. História da sexualidade 2: o uso dos prazeres. Tradução de Maria Thereza da Costa Albuquerque. Rio de janeiro: Edições Graal, 1984.

LA METTRIE. L'homme-Machine. Paris: Éditions Denoël/Gonthier, 1981.

MANDEVILLE, Bernard. La fable des abeilles. Traduction Lucien et Paulete Carrive. Paris: J. Vrin, 1998.

MENIN, Marco. "Jean-Jacques Rousseau vitaliste: La moralisation de l'hygiène médicale entre régime diététique et éthique alimentaire". In: Nuncius, XXVII, 1, 2012.

ROUSSEAU. OEuvres Complètes de Jean-Jacques Rousseau. Ed. Bernard Gagnebin e Marcel Raymond. Paris: Gallimard, 1959-1995. 5 volumes. (Col. Bibliothèque de la Pléiade). 